\title{
Utilization of Numerical Simulation to Predict Spring-back of Dual-Phase Steel Sheet at Bending
}

\author{
$1^{\text {st }}$ David Koreček ${ }^{1}, 2^{\text {nd }}$ Pavel Solfronk ${ }^{2}, 3^{\text {rd }}$ Jiří Sobotka $^{3}, 4^{\text {rd }}$ Michaela Kolnerová $^{4}$ \\ david.korecek@tul.cz'1, pavel.solfronk@tul.cz ${ }^{2}$,jiri.sobotka@tul.cz ${ }^{3}$, michaela.kolnerova@tul.cz ${ }^{4}$
}

Technical University of Liberec, Liberec, Czech Republic, EU ${ }^{1,2,3,4}$

\begin{abstract}
The papers deals with the possibility to predict the spring-back at bending thin sheets with the dual-phase structure in the software PAM-STAMP 2G 2017. Results of the experimental tests are compared with the theoretical calculation performed on the base of final element method - FEM. For utilization the FEM were in the paper defined two computational models and simultaneously there was described methodology how to perform and evaluate the material tests that are necessary to define the individual computational models. In terms of the experimental tests were on the tested material (dual-phase DP 500) performed uni-axial, bi-axial, compression and cyclic tests.
\end{abstract}

Keywords: FEM, Computational Model, Numerical Simulation, Mechanical Tests, Material Characteristics, Yield Criterions

\section{Introduction}

Automobile industry is one of the most dynamic developing segments of the industrial production. That is why there are posed quite strong requirements about rapid implementing of the newest technical and technological innovation on the one hand and on the other hand there is strong effort to achieve the highest efficiency of production - so accompanying with the maximal profit. As one of the methods which makes possible to achieve these goals, there is application of software engineering methods into all production stages. As a great advantage arising from the utilization mathematical approaches at solving problems related with the technological process, there is possibility of their fast application with high variability and immediate obtaining relevant results. So there it is not necessary for planning and realization of the complicated experiments in the given production process. However, as an integral condition of the quality output from numerical simulation there is necessity knowledge not only about the own process but also the selection of the suitable computational model and obtaining accurate input data which define the given computational model.

On the sheet stampings are nowadays posing quite strong requirements mainly in light of their strength, surface quality and dimensional accuracy. Stiffness and strength of the products is mainly influenced by the shape of forming part and selection of material for production given stamping. So as necessary conditions for the proper technological process proposal there is solution of deformation for chosen material to achieve the final shape of stamping in the required quality (to prevent thinning of sheet, sufficient deformation of sheet in the critical zones, waving of sample, to prevent creation of visible face defects, etc.). Problems to achieve shape and dimensional accuracy of forming parts are closely associated with the spring-back of material. Such undesirable effect, which represents the spring-back of material, can be eliminated only by the truly proper proposal of the technological operations and shape correction of stamping tool.

This paper deals with the utilization of the mathematical models to predict the spring-back for sheet stampings and to present influence of the individual computational models on the performed tests. To evaluate possibility of covering influence arising from the Bauschinger effect to predict spring-back by means of the mathematical modelling, there was chosen mathematical model with anisotropic deformation condition termed as Vegter model in combination with isotropic and kinematic hardening of the forming material. Due to fact that high-strength materials are still more and more used in the car-body design, as a testing material was chosen the dual-phase material HCT500X+ZE (marked acc. to EN 10 346) of thickness $0.6 \mathrm{~mm}$. because of its mechanical values there was a presumption to prove an expressive influence of the individual computational models on the results of tests. Such tested material is further in text termed only as DP 500. 


\section{Experimental tests}

\subsection{Static tensile test}

To define the material model Vegter was necessary to carry out the static tensile test, determined the normal anisotropy coefficients in the directions $0^{\circ}, 45^{\circ}$ and $90^{\circ}$ regarding the rolling direction and hydraulic bulge test. Conditions of tests were chosen to be comfortable with the standard EN ISO 6892-1 and EN ISO 10113. From the measured values of static tensile test in the individual directions were subsequently computed the hardening curves of true stress $\sigma$ in dependence on true strain $\varepsilon$. With respect to mathematical definition of hardening curves in model Vegter was made their approximation by power-law function as:

$\sigma=K \cdot\left(\varepsilon+\varepsilon_{0}\right)^{n}$

where:

$\begin{array}{lll}K & \text { strength coefficient } & (\mathrm{MPa}) \\ n & \text { strain hardening exponent } & (-) \\ \varepsilon_{0} & \text { offset of strain } & (-) .[1,2]\end{array}$

Computed fitting constants acc. to equation (1) are, together with values of the normal anisotropy coefficients, summarized in table 1. Hardening curves for the tested material DP 500 regarding the individual directions are shown in fig. 1.

Table 1: Values of the fitting constants and normal anisotropy coefficients in dependence on rolling direction

\begin{tabular}{|c|c|c|c|c|}
\hline $\begin{array}{c}\text { Rolling } \\
\text { direction }\end{array}$ & $\begin{array}{c}\mathbf{K} \\
(\mathbf{M P a})\end{array}$ & $\begin{array}{c}\mathbf{n} \\
(-)\end{array}$ & $\begin{array}{c}\boldsymbol{\varepsilon}_{\mathbf{0}} \\
(-)\end{array}$ & $\begin{array}{c}\mathbf{R} \\
(-)\end{array}$ \\
\hline $0^{\circ}$ & 817 & 0,1556 & 0,001 & 0,7574 \\
\hline $45^{\circ}$ & 823 & 0,1661 & 0,0009 & 0,9459 \\
\hline $90^{\circ}$ & 833 & 0,1624 & 0,0008 & 0,9076 \\
\hline
\end{tabular}
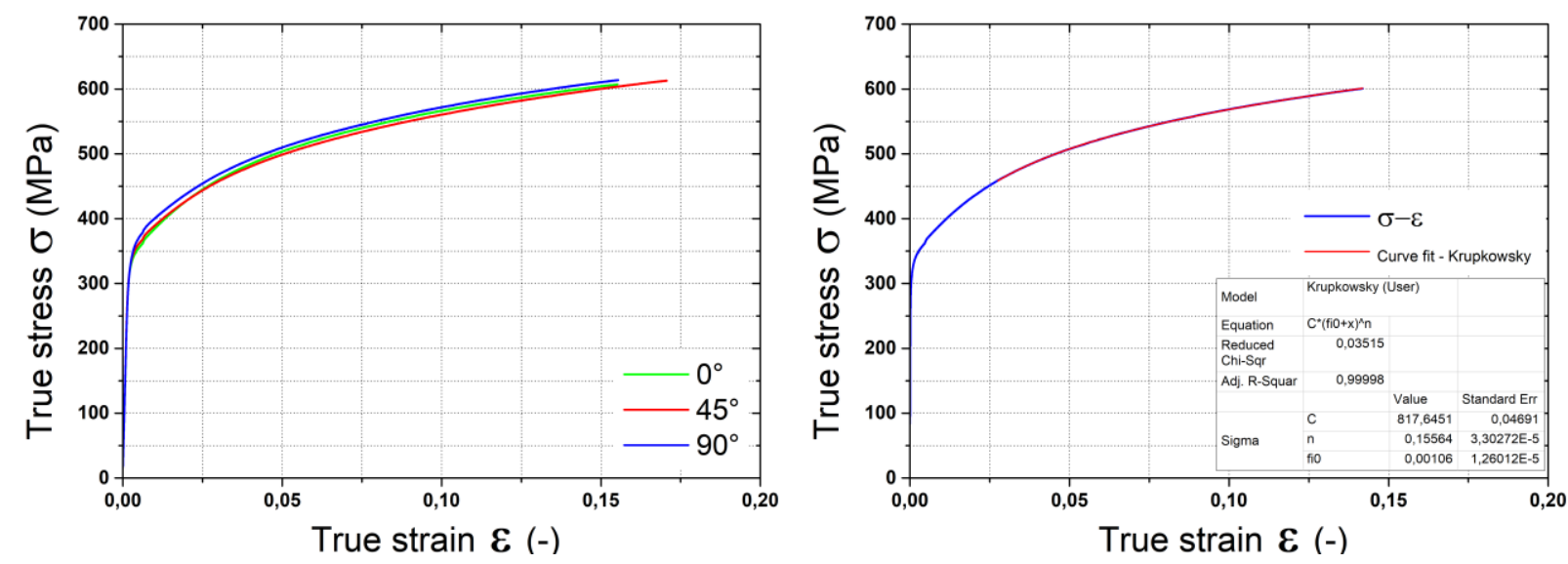

Fig. 1. Hardening curves from the static tensile test - DP 500

\subsection{Hydraulic bulge test}

For proper definition of the Vegter yield criterion is especially necessary to carry out the so-called hydraulic bulge test (HBT). The hydraulic bulge test represented the second major part of the experiment. For this test is very important fact that there is bi-axial stress state cause it is very important "point" for the future utilization in the different yield criterions. Due to the different stress state in comparison to the static tensile test, for its stress-strain curve it is necessary to compute so-called effective stress $\sigma_{\mathrm{EF}}(\mathrm{MPa})$ and effective strain $\varepsilon_{\mathrm{EF}}$. Computation of all important values is summarized by means of equation (2), (3) and (4). [1] 


$$
\begin{aligned}
& \sigma_{E F}=\frac{p R}{2 t} \\
& \varepsilon_{E F}=\frac{2 \sqrt{3}}{3} \sqrt{\varepsilon_{1}^{2}+\varepsilon_{1} \varepsilon_{2}+\varepsilon_{2}^{2}}=\varepsilon_{3} \\
& t=t_{0} e^{\varepsilon_{3}}
\end{aligned}
$$

where:

$\begin{array}{lll}\sigma_{E F} & \text { effective stress } & (\mathrm{MPa}) \\ p & \text { pressure } & (\mathrm{MPa}) \\ \varepsilon_{E F} & \text { effective strain } & (-) \\ R & \text { radius of curvature } & (\mathrm{mm}) \\ \varepsilon_{l, 2,3} & \text { true strains } & (-) \\ t, t_{0} & \text { actual and initial thickness } & (\mathrm{mm}) .\end{array}$

For the own measurement of the hydraulic bulge test there was used the contact-less optical system ARAMIS. The principle of such measurement is shown in Fig. 2. Measured material is placed between upper and lower blank-holders and two scanning cameras are added right before the tested material DP 500.

As the whole evolution of the hydraulic bulge test was scanned by the contact-less optical system ARAMIS, subsequently it was possible to compute distribution of both major strain $\varepsilon_{1}$ and minor strain $\varepsilon_{2}$ within the required area (top of the sphere). Due to that was also possible to compute strain in the thickness direction $\varepsilon_{3}$ which is important to know for computation actual thickness - see equation (4). Finally by fitting best-fit sphere over computed part it was possible to find out required radius of curvature $\mathrm{R}$ [mm]. After that it was possible with equations (2), (3) and (4) to compute effective stress $\sigma_{\mathrm{EF}}$ and effective strain $\varepsilon_{\mathrm{EF}}$ and to plot stress-strain curve for the bi-axial stretching state of stress (the hydraulic bulge test). From these values was subsequently created the scatter plot - see Fig. 3. It is not possible to use continuous increasing of pressure due to time delay in sensor and hoses. After that was also used (as in the case of the static tensile test) the power-law equation acc. to Swift-Krupkowsky and via fitting (nonlinear curve fit) was computed the hardening curve and all constants (K, $\mathrm{n}, \varepsilon_{0}$ ). Values of these constants for the hydraulic bulge test were as following: $\mathrm{K}=948 \mathrm{MPa}, \mathrm{n}=0.2355$ and $\varepsilon_{0}$ $=0.00289$. Such values are truly very important to compute the very significant bi-axial point in the advanced computational models in numerical simulations (e.g. for Vegter yield criterion). Beside values of uni-axial tensile (eventually compression) point and normal anisotropy coefficients are these values the crucial for proper computation of required yield criterion. $[1,2]$

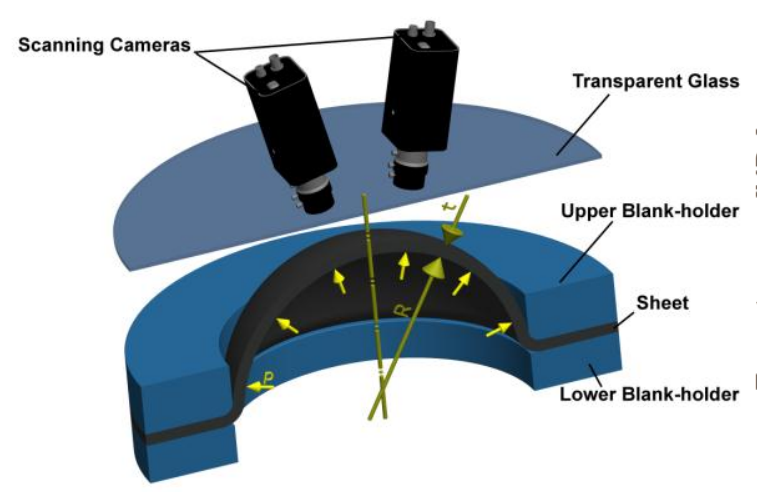

Fig. 2. Principle of the hydraulic bulge test with utilization of the contact-less optical system ARAMIS

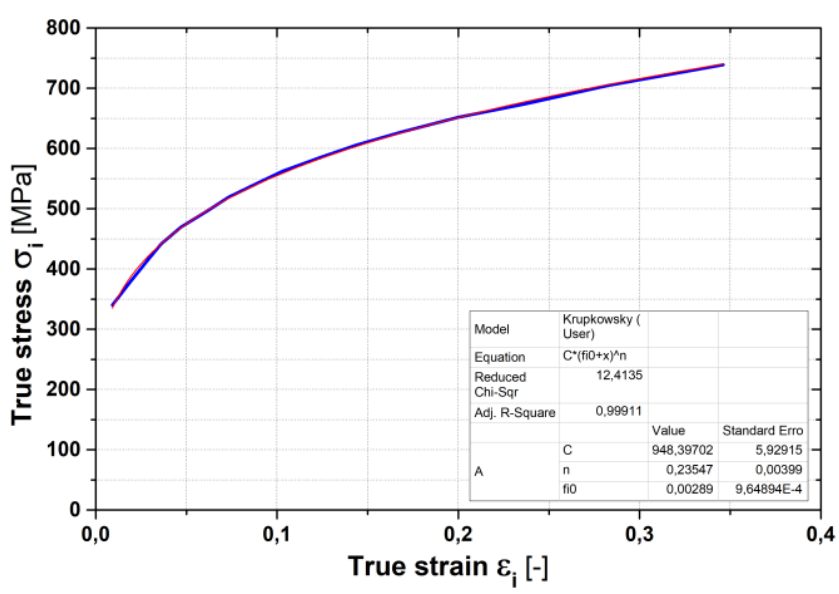

Fig. 3. Results from the HBT - DP 500

\subsection{Cyclic test}

To define the material model termed as Yoshida-Uemori there is needed to carry out such cyclic test under that can take effect the change in sense $(+,-)$ of the tested sample loading. Due to the compressive stress states is carrying out of this test for sheet samples very demanding and there is loss of stability resulting as sample buckling. Because of these reasons was at Department of Engineering Technology designed the testing jig which enables to carry out cyclic test for sheet sample on the device for the static tensile test. Such testing jig 
was designed as additional device of the clamping grips. Testing jig consists of four subdivided supporting grips that are hydraulically controlled and prevent the sheet sample from buckling during the compression. Strain magnitude is recorded by the contact length-gauge with high accuracy. As a result from test there is cyclically repeating course of tensile and compressive stress in dependence on deformation. The offset of individual measured curves from monitored cycles rests in the magnitude of Bauschinger effect for tested material. Own lay-out arrangement of the cyclic test is clearly shown in fig. 4. Results of the measured magnitudes are evident from the graph which is shown in fig. 5. [3, 4]
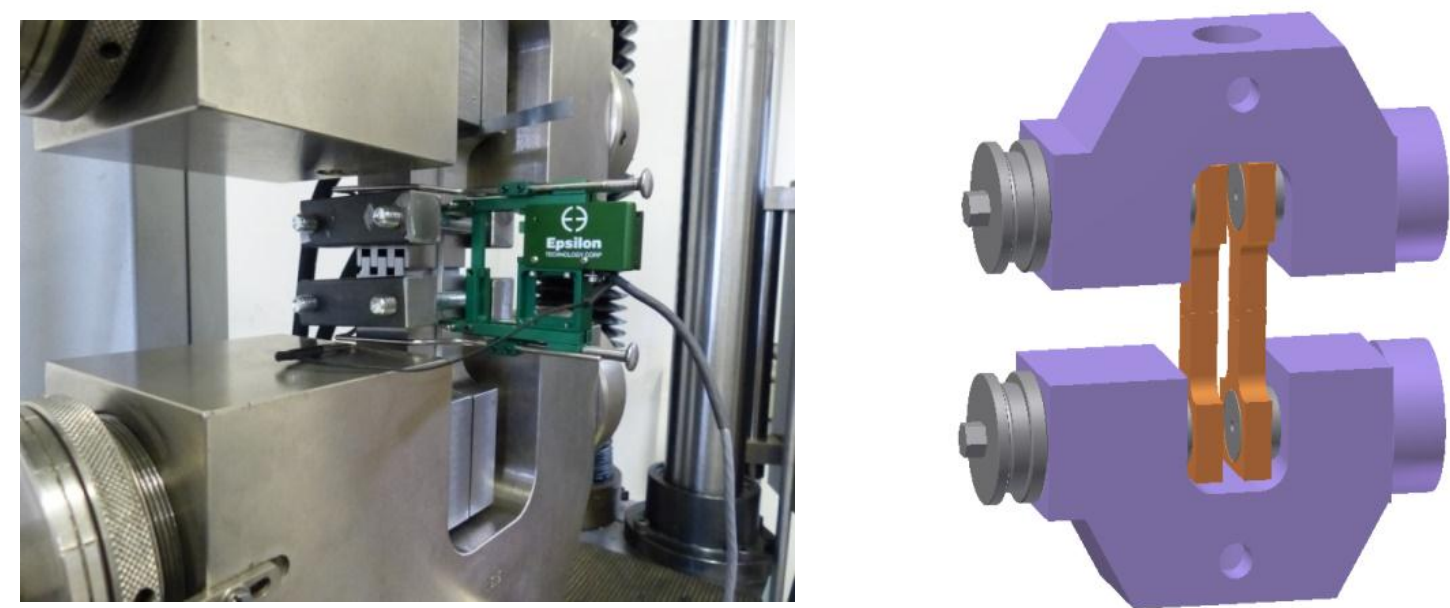

Fig. 4. Arrangement of the cyclic test on the device TIRA Test 2300

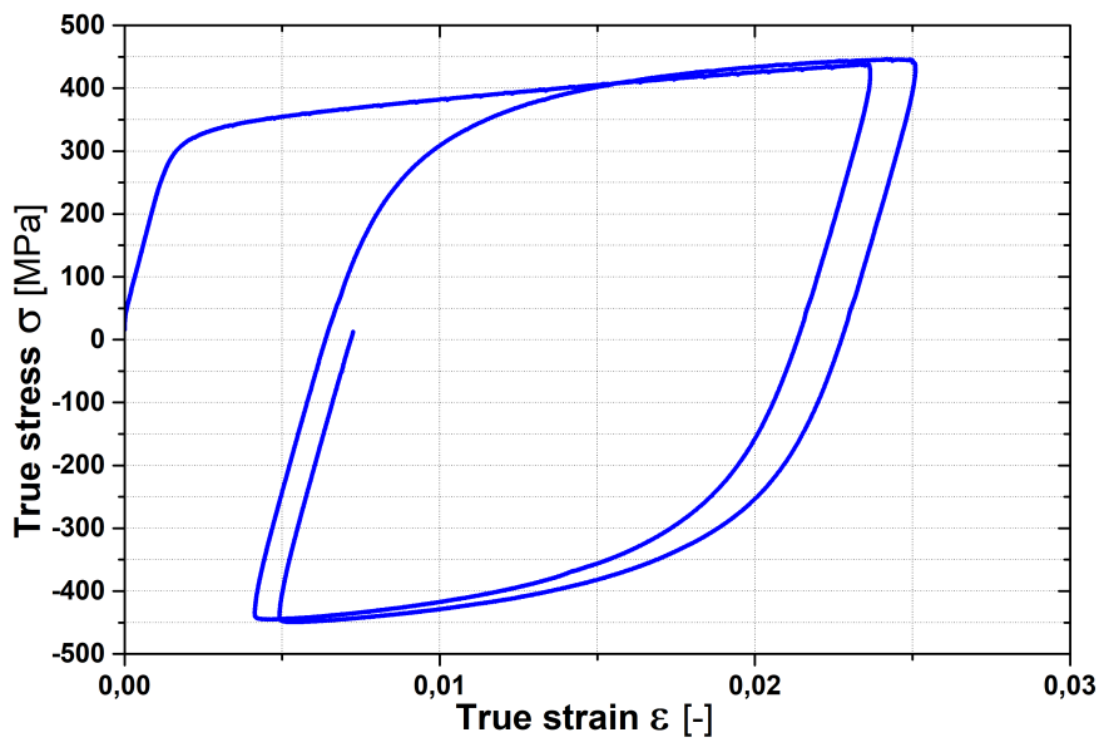

Fig. 5. Cyclic test results for the stainless material DP 500

\subsection{U-die bending}

There was used simple blank and U-die bending to experimentally verify the value of spring.-back. Such bending was performed on the testing device TIRA Test 2300. After termination of test was sheet sample subjected to the dimensional and shape analysis on the 3D coordinate measuring device SOMET XYZ 464 with the involved software TANGO!3D for own evaluation. As a result of the experimental measurement there is system of points in the *.step format that copies the real shape of sample. Sheet circumference is defined by the 70 measured points and a relevant result is evident from fig. 6. Obtained sheet contour is subsequently used as a comparison criterion to verify matching between experiment and numerical simulation from PAM-STAMP 2G. 

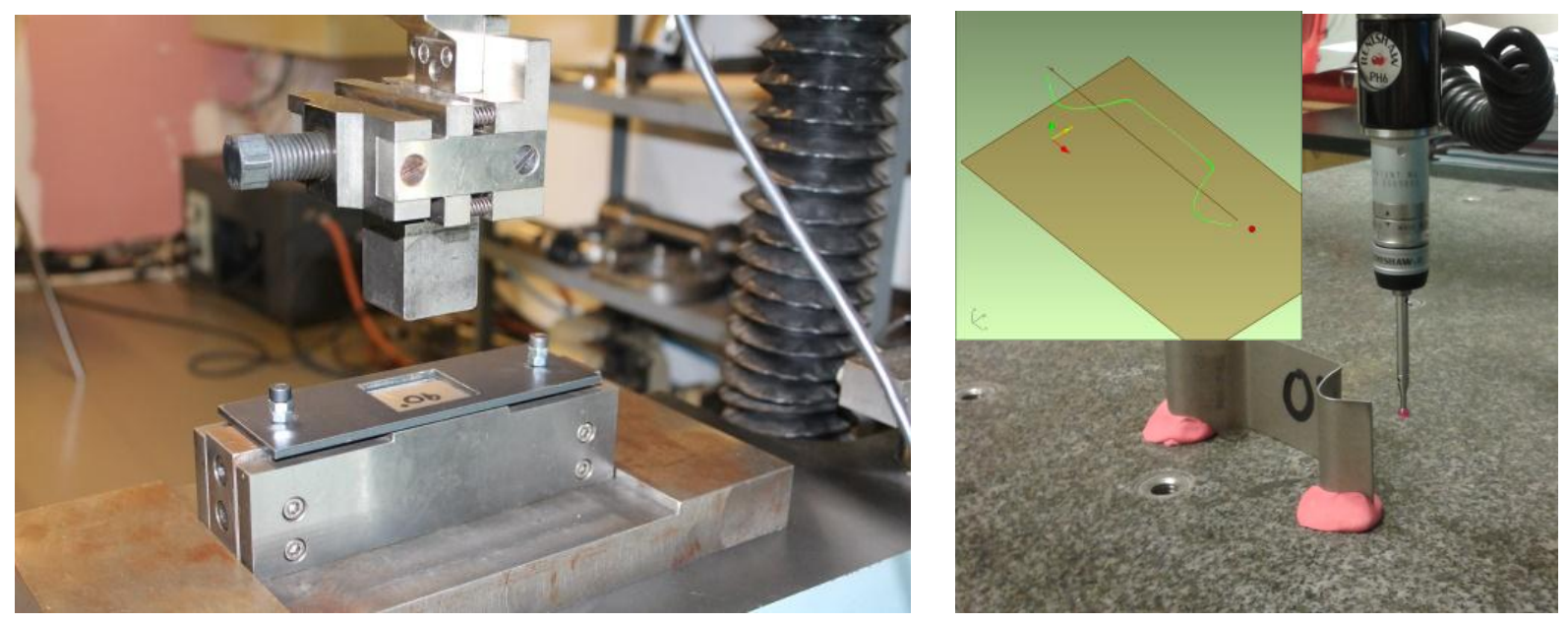

Fig. 6. Arrangement of the U-die bending on the device TIRA Test 2300 and measurement of contour after bending

\section{Numerical simulation of the bending process}

\subsection{Definition of the material model}

For definition the material model termed as Vegter Isotropic was used anisotropic yield locus which takes into account different material deformation behaviour in the directions $0^{\circ}, 45^{\circ}$ and $90^{\circ}$ regarding the rolling direction in combination with the isotropic hardening. So this hardening model doesn't cover Bauschinger effect during change of loading direction $(+,-)$ in the forming material $[5,6]$. To properly define Vegter isotropic model is necessary to apply following material properties and characteristics:

- Young's modulus in tension E

- Poisson's ratio $\mu$

- Density $\rho$

- Static tensile test for rolling directions $0^{\circ}, 45^{\circ}$ a $90^{\circ}$ (mean hardening curve in the relevant directions)

- Normal anisotropy coefficients for rolling directions $0^{\circ}, 45^{\circ}, 90^{\circ}$

- Hydraulic Bulge test (to define multi-axial stress state)

As the second material model used in this paper, there was model termed as Vegter Kinematic Yoshida model. It is anisotropic yield locus which covers the different deformation behaviour of material in the directions $0^{\circ}, 45^{\circ}$ and $90^{\circ}$ regarding the rolling direction and moreover, in combination with the kinematic hardening of the material. As a great advantage there is fact, that such model takes into account also Bauschinger effect during change of loading direction $(+,-)$ in the forming material. So there presumptions make the second used model (Vegter Kinematic Yoshida) a little bit better in light of accuracy in comparison to the first used mathematical model Vegter Isotropic. [5, 6]

On the other hand, to define material model Vegter Kinematic Yoshida, there is necessary to add also results from the cyclic test (for the previously mentioned material properties). Material datasheets of the both mathematical models as well as both isotropic and kinematic hardening of material which were used for the numerical simulation in the environment PAM-STAMP 2G are shown in fig. 7 and 8. 


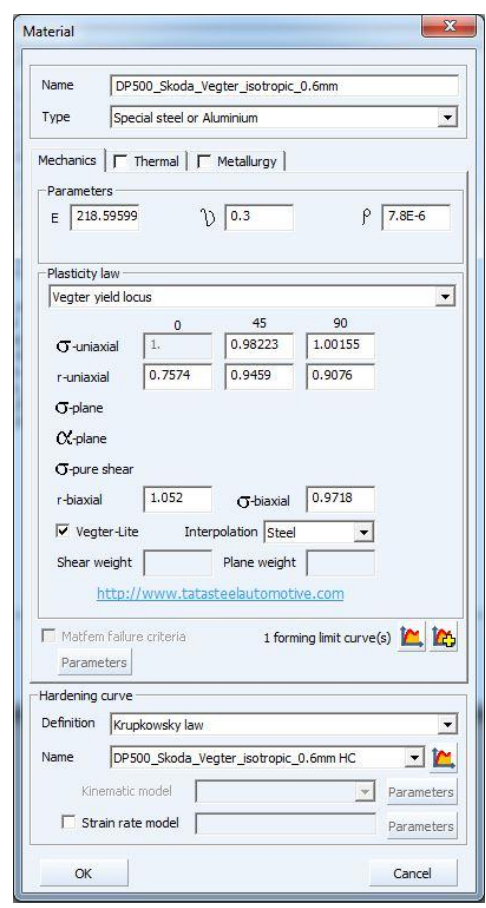

Yield Locus definition

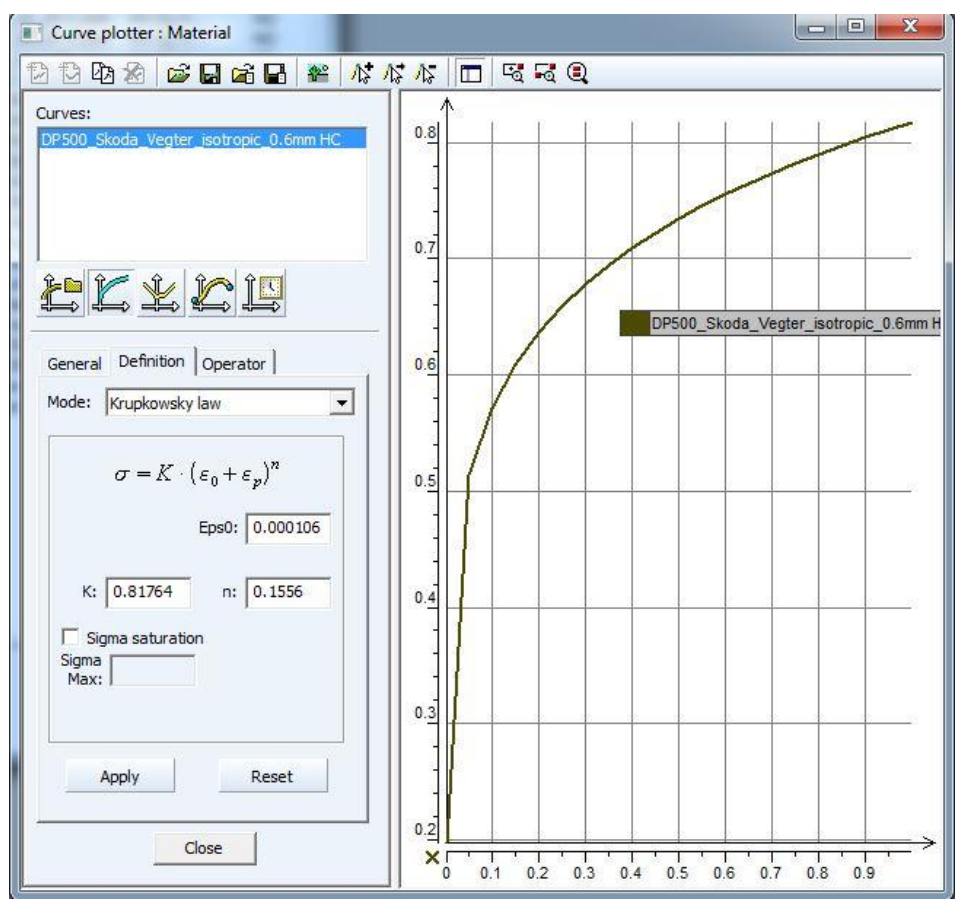

Parameters for isotropic hardening of material

Fig. 7. Material datasheet in the PAM-STAMP 2G for model Vegter Isotropic

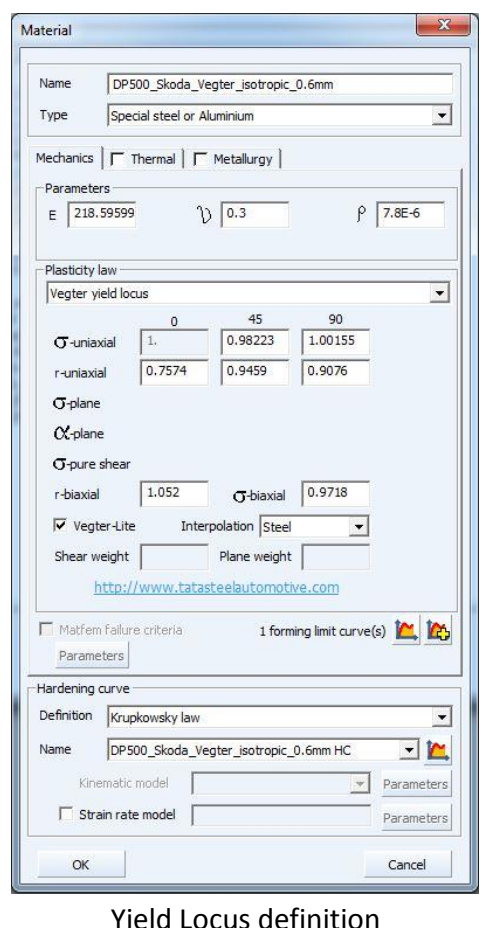

Yield Locus definition

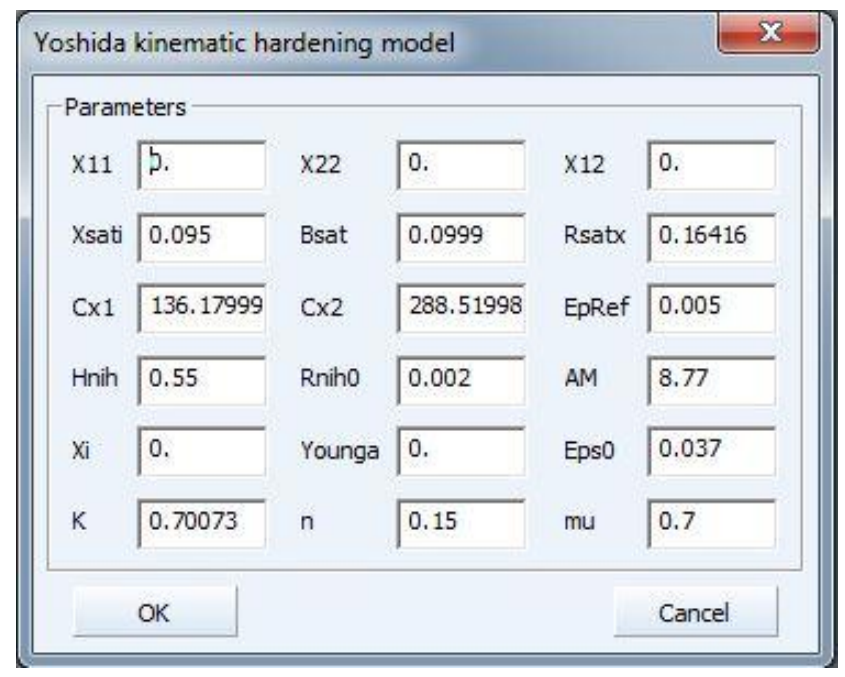

Parameters for kinematic hardening of material - Yoshida

Fig. 8. Material datasheet in the PAM-STAMP $2 \mathrm{G}$ for model Vegter Kinematic Yoshida

\subsection{Definition of the FEM project}

Boundary conditions of the numerical simulations were set in just manner to correspond the performed experiment. Geometry of the active tool surfaces was created in the software Catia V5 and was imported into the environment PAM-STAMP 2G. Initial adjustment of the FEM project (in PAM-STAMP 2G) is shown in fig. 9a. Result of the numerical simulation after bending and spring-back is evident from fig. $9 \mathrm{~b}$. 


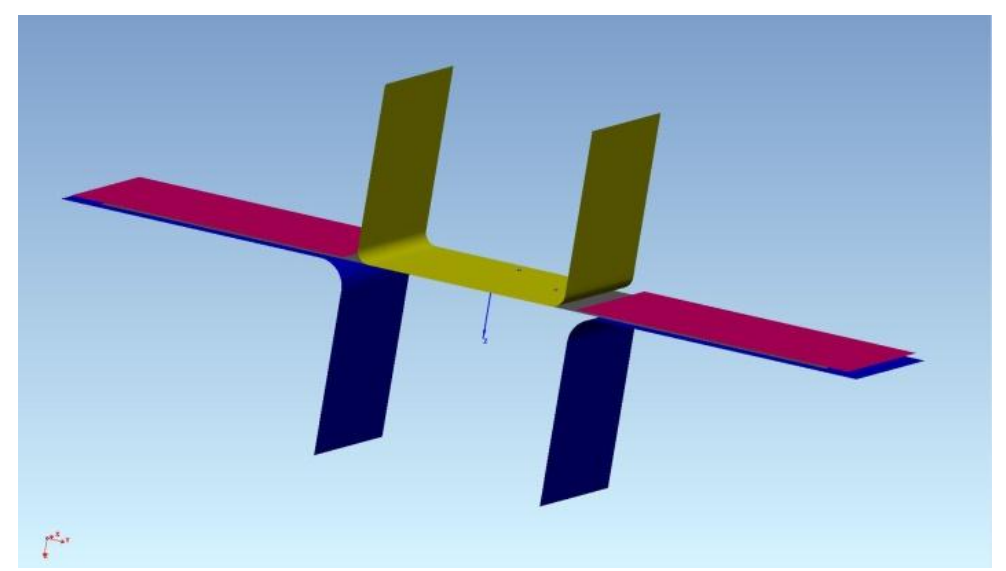

Project adjustment in the environment PAM-STAMP 2 G
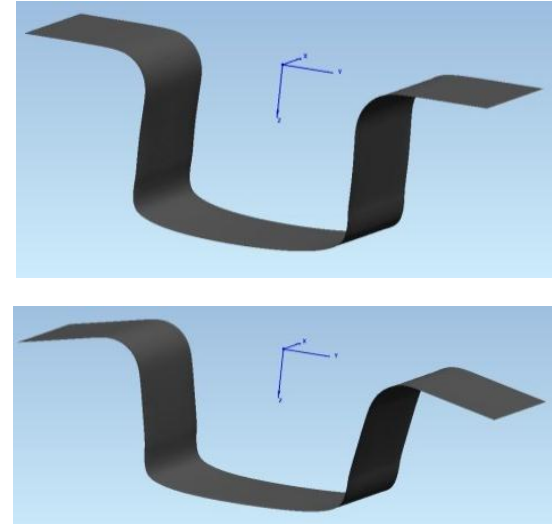

Numerical simulation after bending and spring-back

Fig. 9. Example of computation bending process (inc. spring-back)

\section{Results}

Accuracy of the performed FEM computation was evaluated acc. to matching between the real sample contour and results from the numerical simulation from both used computational models. In fig. 10 is shown comparison of contours for samples already after spring-back computation. Yellow contour corresponds to the shape of the experimentally measured sample (so it serves as the reference sample). Red contour belongs to the shape of sample revealed from the numerical simulation by using model Vegter Kinematic Yoshida and finally blue contour represents the shape revealed from the numerical simulation by using model Vegter Isotropic.

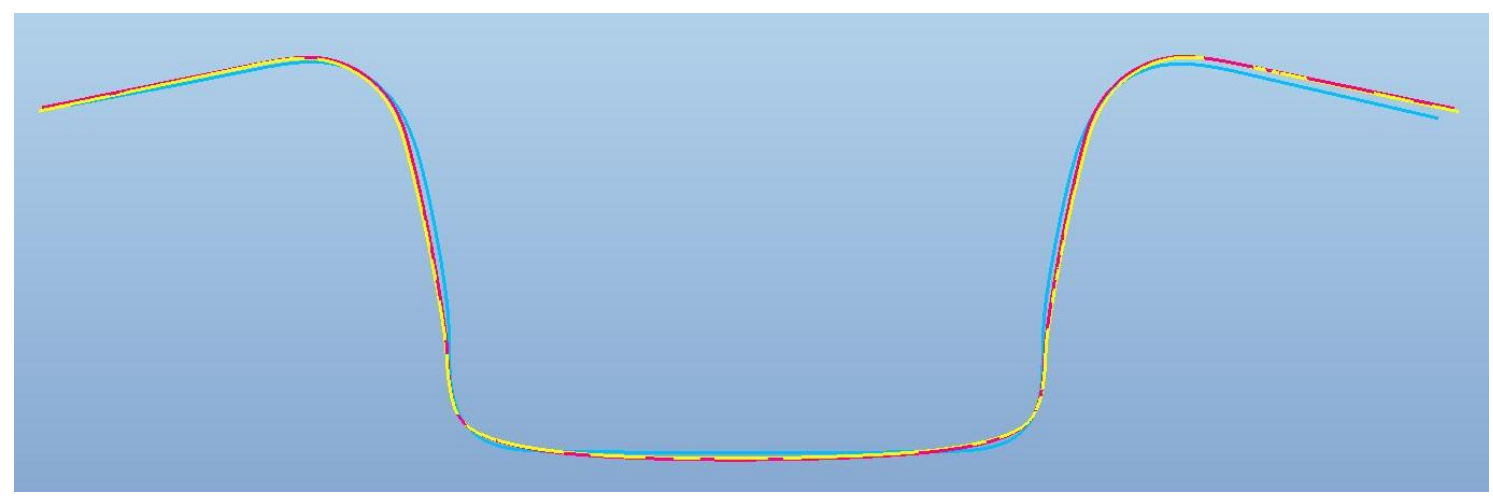

Fig. 10. Cyclic test results for the stainless material DP 500

\section{Conclusion}

From the performed experimental tests and numerical simulations is evident that selection of the computational model greatly influence the final spring-back prediction accuracy at the numerical simulation of the bending process numerical simulation. On the other hand, there are almost neglectable differences between results from the experiment part and numerical simulations in light of utilization material models that combine anisotropic yield locus with the kinematic hardening of material. 


\section{Acknowledgements}

This publication was written at the Technical University of Liberec as part of the Student Grant Contest "SGS 21179" with the support of the Specific University Research Grant, as provided by the Ministry of Education, Youth and Sports of the Czech Republic in the year 2017.

\section{References}

[1] ASM HANDBOOK. Volume 8 - Mechanical Testing and Evaluation. 10th ed. Materials Park: ASM International, 2000. s. 998. ISBN 0-87170-389-0.

[2] HOSFORD, W.F., CADDEL, R. Metal Forming (Mechanics and Metallurgy). 3rd ed. New York: Cambridge University Press, 2007. s. 312. ISBN 978-0-521-88151-0.

[3] YOSHIDA, F., UEMORI, T. A model of large-strain cyclic plasticity and its application to springback simulation. International Journal of Mechanical Sciences, October 2003, Vol. 45, No. 10., pp 1687-1702. ISSN 0020-7403

[4] SHUN-LAI, Z., et al. Evaluating the significance of hardening behavior and unloading modulus under strain reversal in sheet springback prediction. International Journal of Mechanical Sciences, December 2013, Vol. 77, pp 194-204. ISSN 0020-7403

[5] TAHERIZADEH, A., et al. Finite element simulation of springback for a channel draw process with drawbead using different hardening models. International Journal of Mechanical Sciences, April 2009, Vol. 51, No. 4., pp 314-325. ISSN 0020-7403

[6] BANABIC, D. ed. Formability of Metallic Materials: Plastic Anisotropy, Formability Testing, Forming Limits. Berlin: Springer-Verlag, 2000. s. 344. ISBN 978-3-642-08750-9 